\title{
METASTASISING LEIOMYOMA- A CASE REPORT
}

\author{
Krishna Govindan ${ }^{1}$, Sheela Kuzhiveli Mohammed Ali², Lekshmy Kausthubham Sudheendran ${ }^{3}$
}

1 Professor and HOD, Department of Pathology, Government Medical College, Trivandrum, Kerala, India.

${ }^{2}$ Assistant Professor, Department of Pathology, Government Medical College, Trivandrum, Kerala, India.

3 Junior Resident, Department of Pathology, Government Medical College, Trivandrum, Kerala, India.

HOW TO CITE THIS ARTICLE: Govindan K, Ali SKM, Sudheendran LK. Metastasising leiomyoma- a case report. J. Evolution Med. Dent. Sci. 2018;7(42):4591-4595, DOI: 10.14260/jemds/2018/1024

\section{PRESENTATION OF CASE}

Benign Metastasising Leiomyoma (BML) is defined as the benign proliferation of smooth muscle in organs such as lung or lymph node etc. in a patient with benign uterine smooth muscle tumour. BML is a rare condition. It is more prevalent in women of late childbearing age. The aetiology is unknown. But there are several theories explaining the pathophysiology. ${ }^{1}$ Two important theories are: (1) Metastasis from an existing leiomyoma or (2) Multicentric leiomyomatous growths rather than actual metastases. ${ }^{1}$ Most of the patients with BML have a history of uterine leiomyoma and/ or myomectomy. Steiner was the first to describe this disease in detail in 1939.2,3 The most common site of metastasis is lung. Other important sites are paraaortic lymph nodes, abdominal lymph nodes, heart, breasts, liver, oesophagus, trachea, limb, striated muscles, skeletal muscle, skin, scars and central nervous system.2,4,5,6,7 BML shows positivity for both oestrogen and progesterone receptors.

Our case is that of metastasis to pancreas and adrenal, which developed 11 years after hysterectomy for leiomyomas. Literature review did not reveal any such case.

A 51-year-old multiparous female was referred from a peripheral hospital for complaints of upper abdominal pain and back ache of 2 months' duration. There was no history of loss of appetite, loss of weight, jaundice, melena or haematuria. She has past history of hysterectomy, which was done 11 years ago. There were no other abnormal menstrual history or relevant past medical history and family history. On examination, abdomen was soft and there was mild tenderness in the epigastrium. All other systems were within normal limits. Radiological investigations of abdomen and pelvis revealed well defined space occupying lesion in the neck of pancreas and right adrenal gland.

\section{DIFFERENTIAL DIAGNOSIS}

The main differential diagnosis were pheochromocytoma, adrenal cortical carcinoma/adenoma, adrenal metastasis from pancreatic neoplasm.

\section{CLINICAL DIAGNOSIS}

The clinical diagnosis was pancreatic neuroendocrine tumour with metastasis to right adrenal. Whipple's procedure was done along with right adrenalectomy.

'Financial or Other Competing Interest': None.

Submission 12-03-2018, Peer Review 25-09-2018,

Acceptance 03-10-2018, Published 15-10-2018.

Corresponding Author:

Dr. Krishna Govindan,

Professor and HOD,

Department of Pathology,

Government Medical College, Trivandrum, Kerala, India.

E-mail: drkrishnagovindan@gmail.com

DOI: $10.14260 /$ jemds/2018/1024

\section{PATHOLOGICAL DISCUSSION}

On gross examination, fairly circumscribed grey white firm lesion with cystic degeneration and areas of haemorrhage was noted in the head of pancreas and right adrenal measuring $3 \times 2.4 \times 3.5 \mathrm{~cm}$ and $4.5 \times 3 \times 2 \mathrm{~cm}$ respectively. Adrenalectomy specimen weighed 36 grams. Microscopic examination of both lesions showed similar neoplasm composed of cells arranged in interlacing fascicles. Individual cells are long spindly with moderate eosinophilic cytoplasm, elongated vesicular nuclei with blunt ends and fine chromatin. Mitotic figures were less than 5/10 hpf. Tumour cells showed positivity for Caldesmon, Desmin, SMA, Vimentin, oestrogen receptor and progesterone receptor and negative for S100, CD 117, CD 34, CD 99; Ki 67 index was low. Correlating the past history with the current morphological features and immunohistochemical studies, a diagnosis of metastasising leiomyoma to pancreas and adrenal was given. Patient is being followed up and is currently doing well.

\section{Lab Findings}

- $\quad$ Routine blood investigations were within normal limits.

- Liver function test and renal function test were within normal limits.

- Serum calcium, phosphate, parathyroid hormone, CGA and DHEA were within normal limits.

- 24-hour urine metanephrine was normal.

- CA-99 was within normal limits.

- CT scan of abdomen and pelvis:

- Neck of the pancreas shows a space occupying lesion measuring $3.1 \times 3.1 \times 3.5 \mathrm{~cm}$ with welldefined margins and heterogeneous density extending to adjacent head region. Imaging features are suggestive of pancreatic endocrine neoplasm.

- $\quad$ Right adrenal showed a well-defined isodense space occupying lesion measuring $4.4 \times 4.3 \times 6.2 \mathrm{~cm}$ and the differential diagnosis were pheochromocytoma, adrenal adenoma and adrenal metastasis from pancreatic neoplasm.

- $\quad$ CT Chest: Within normal limits.

We received pylorus preserving pancreaticoduodenectomy specimen with portion of duodenum measuring $25 \mathrm{~cm}$ in length, head of pancreas measure $6 \times 7 \times 4.5 \mathrm{~cm}$ and gall bladder measures $9 \mathrm{~cm}$ in length. Cutting through the antimesenteric border of duodenum, mucosa was unremarkable. Surface of the pancreas shows a blackish nodular projection at the neck region. Cut section of pancreas identified a fairly circumscribed lesion measuring 3 x 2.4 x $3.5 \mathrm{~cm}$. Cut section was grey-white firm with areas of cystic change. Rest of the pancreas was grey-white and lobulated. Also received right adrenalectomy specimen weighing 38 grams and measuring $5.5 \times 4 \times 3.2 \mathrm{~cm}$. Cut section identified a circumscribed grey-white firm lesion with tiny cystic spaces 
and specks of haemorrhage measuring $4.5 \times 3 \times 2 \mathrm{~cm}$. Normal adrenal gland was noted towards the periphery.

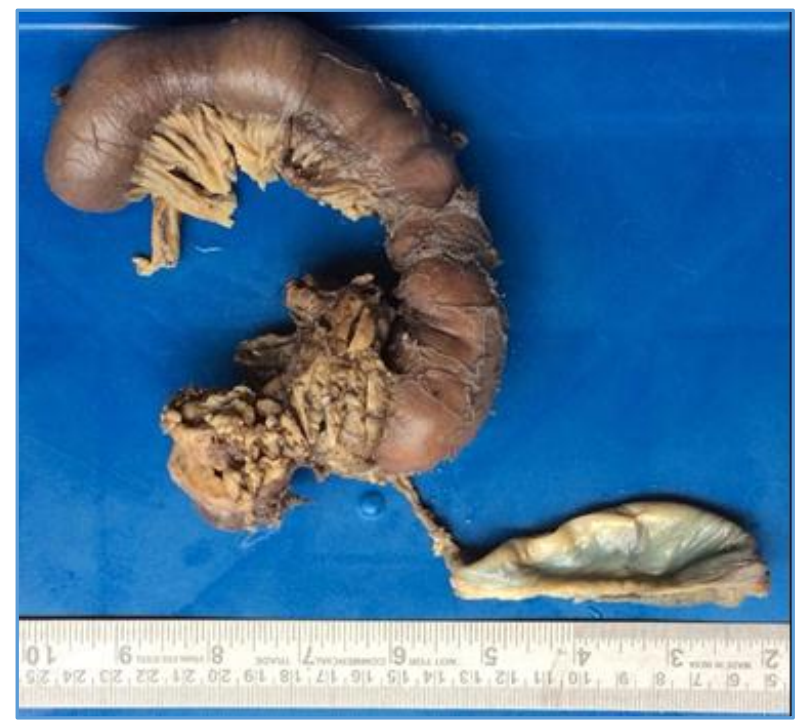

Figure 1. Pylorus preserving Pancreaticoduodenectomy Specimen

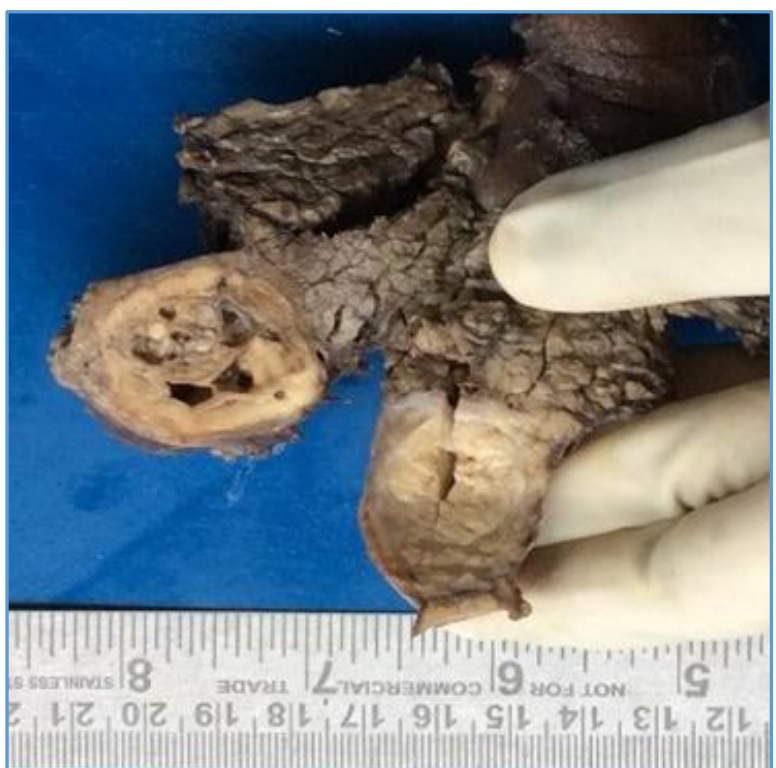

Figure 2. Cut Section of Pancreas showing Circumscribed Grey-White Lesion with Cystic Change

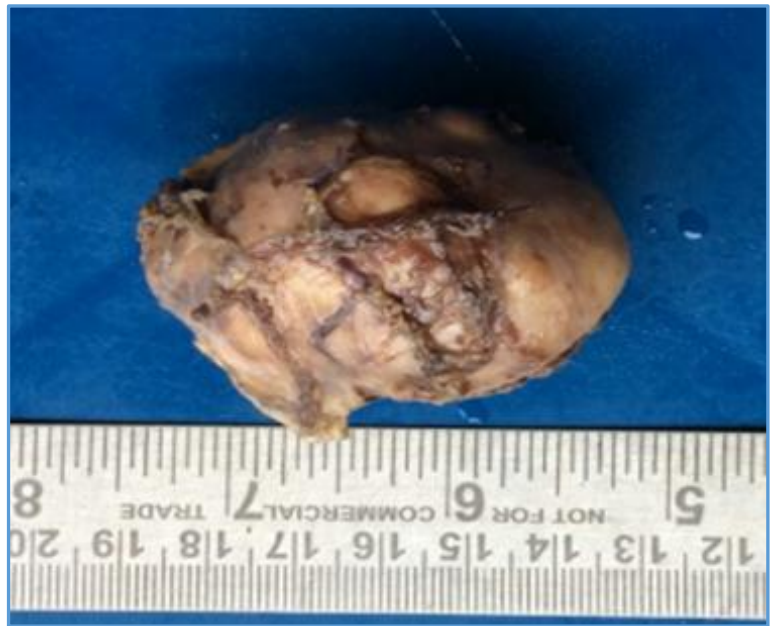

Figure 3. Adrenalectomy Specimen

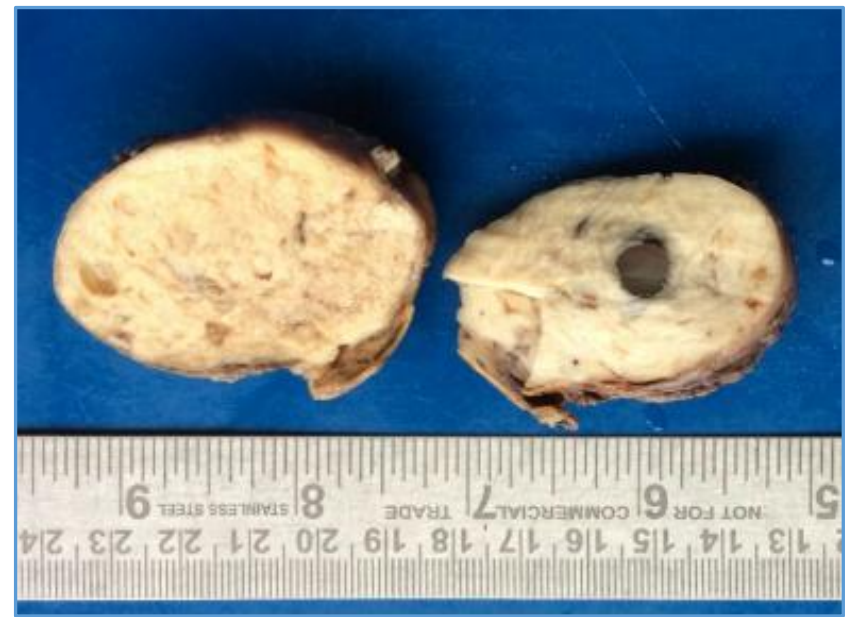

Figure 4. Cut Section of Adrenalectomy Specimen

Histologically, sections from both pancreas and adrenal showed a circumscribed cellular neoplasm composed of cells arranged in interlacing fascicles and bundles. Individual cells are long spindly with moderate eosinophilic cytoplasm, elongated vesicular nucleus with blunt ends and fine chromatin. Mitosis was $<5 / 10 \mathrm{hpf}$. Immunohistochemical study was done.

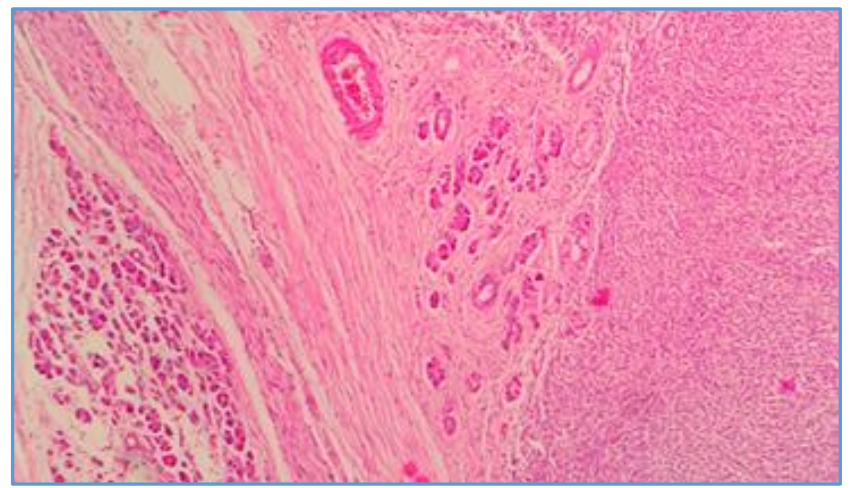

Figure 5. Tumour with Adjacent Pancreas (100x)

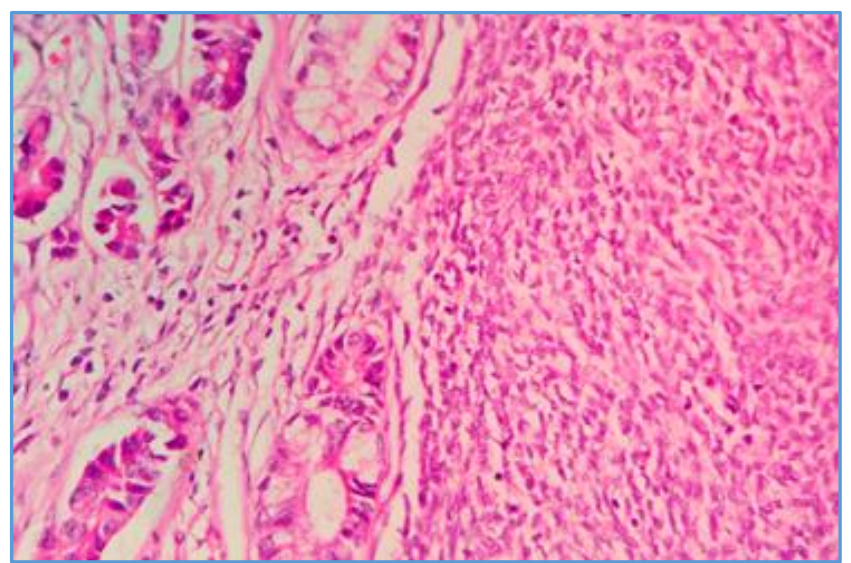

Figure 6. Tumour with Adjacent Pancreas (400x) 


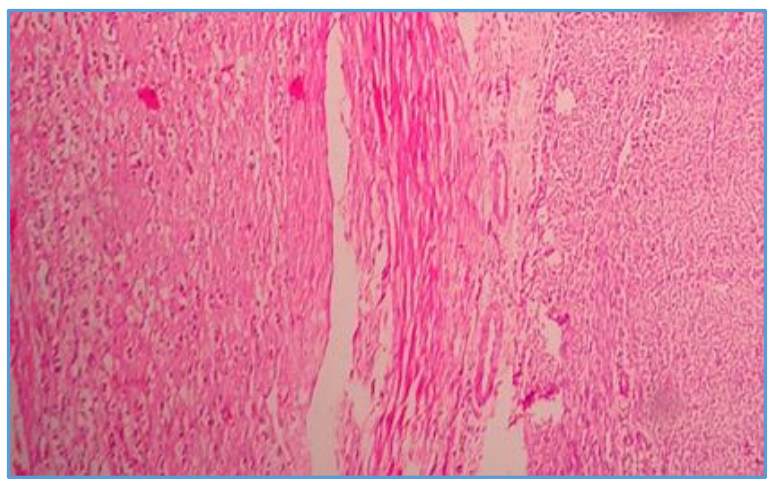

Figure 7. Tumour with Adjacent Adrenal (100x)

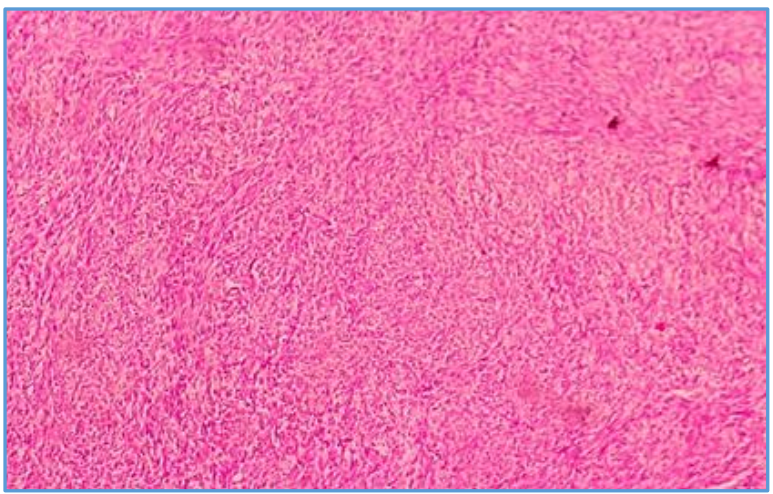

Figure 8. Tumour (100x)

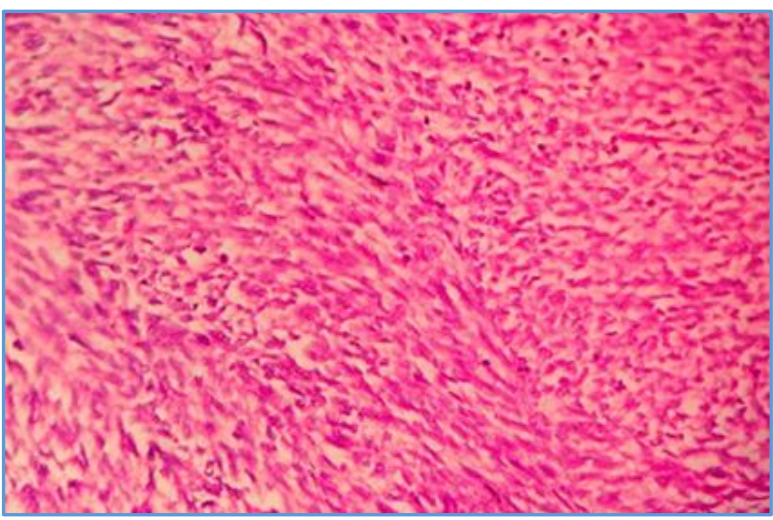

Figure 9. Tumour (400x)

Tumour cells showed positivity for Caldesmon, desmin, SMA, Vimentin, oestrogen receptor and progesterone receptor. Negative for S100, CD 117, CD 34 and CD 99. Ki 67 index was low.

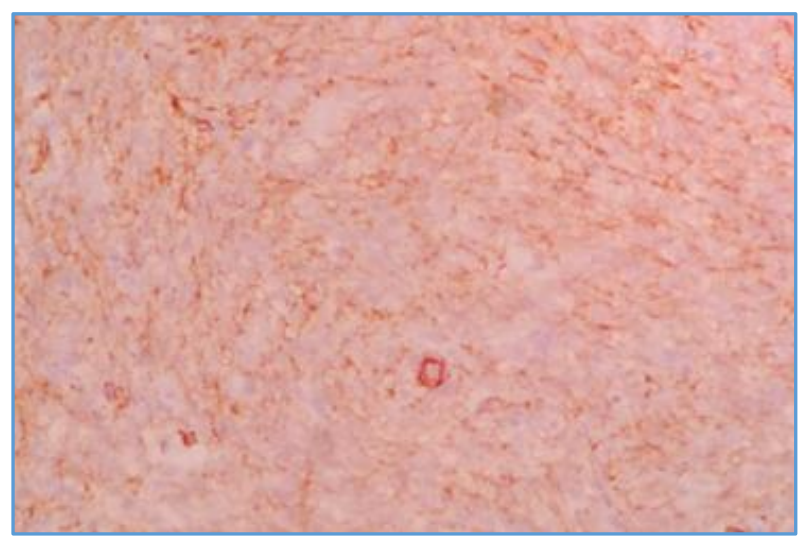

Figure 10. Tumour Cells showing Caldesmon Positivity

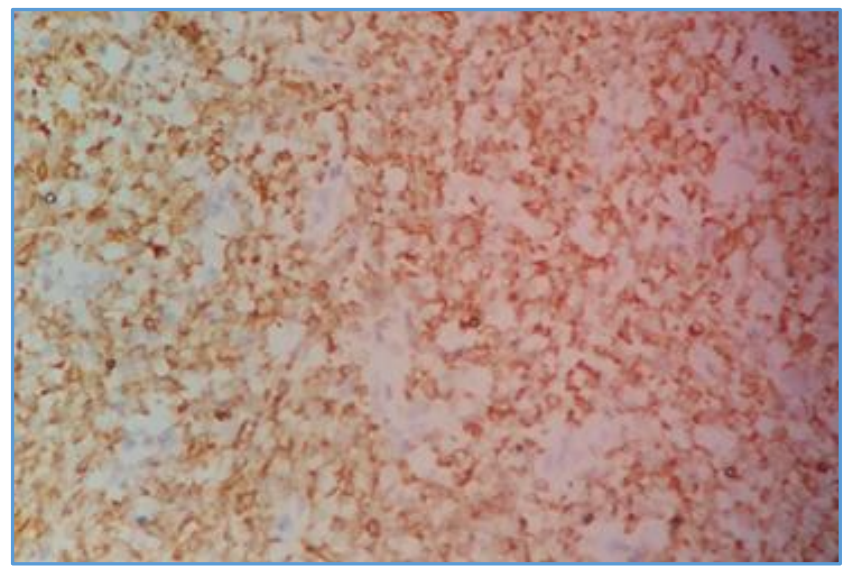

Figure 11. Tumour Cells showing Desmin Positivity

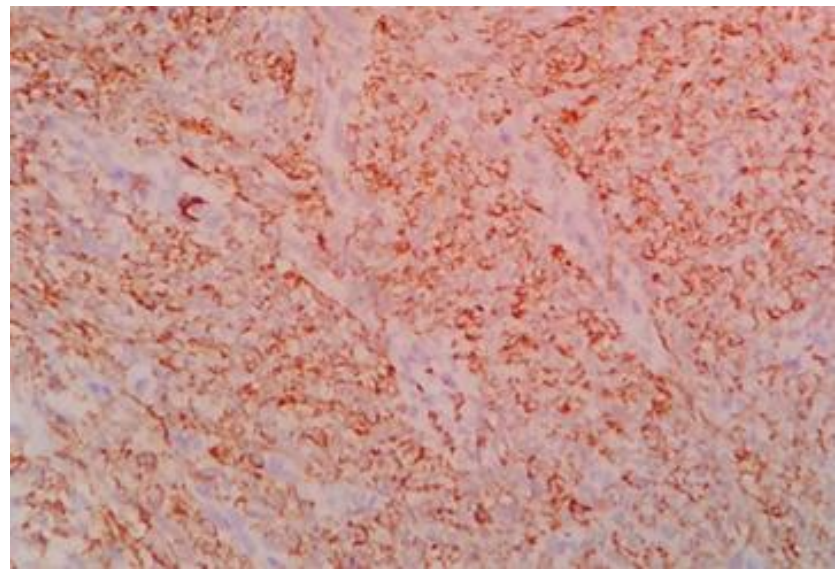

Figure 12. Tumour Cells showing SMA Positivity

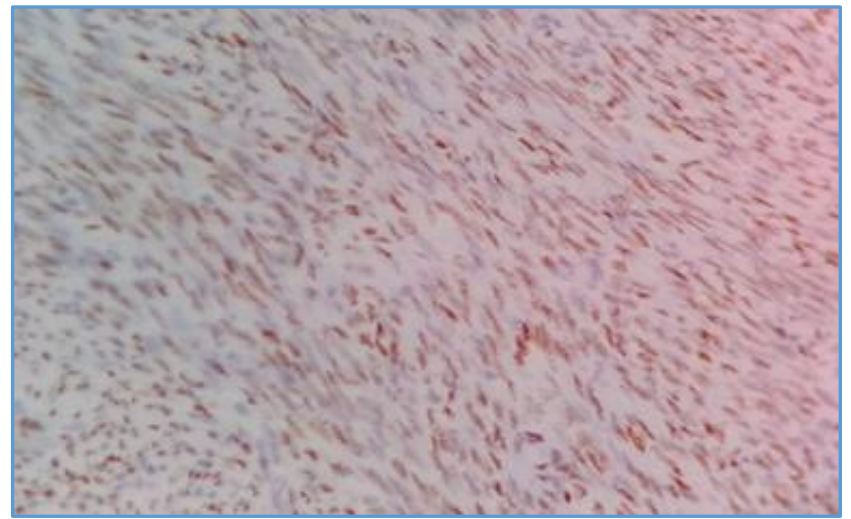

Figure 13. Tumour Cells showing ER Positivity

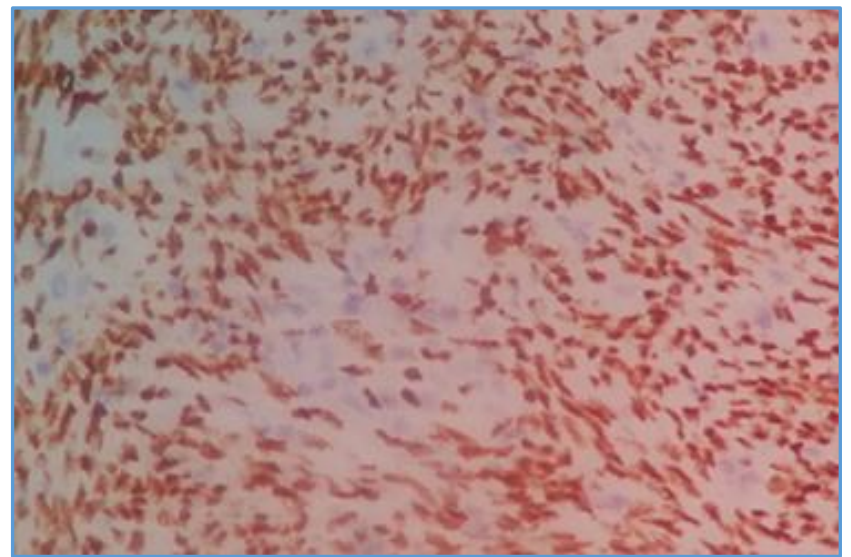

Figure 14. Tumour Cells showing PR Positivity 


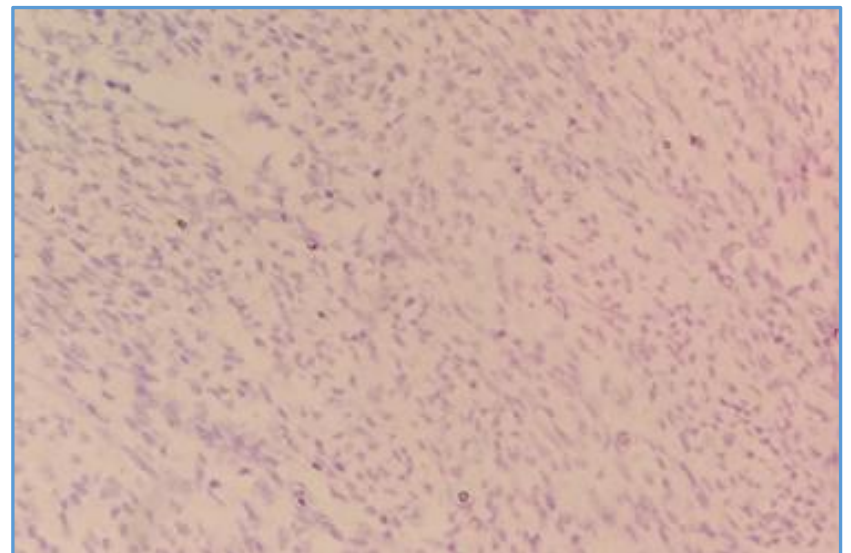

Figure 15. Tumour with Negative Staining for S100

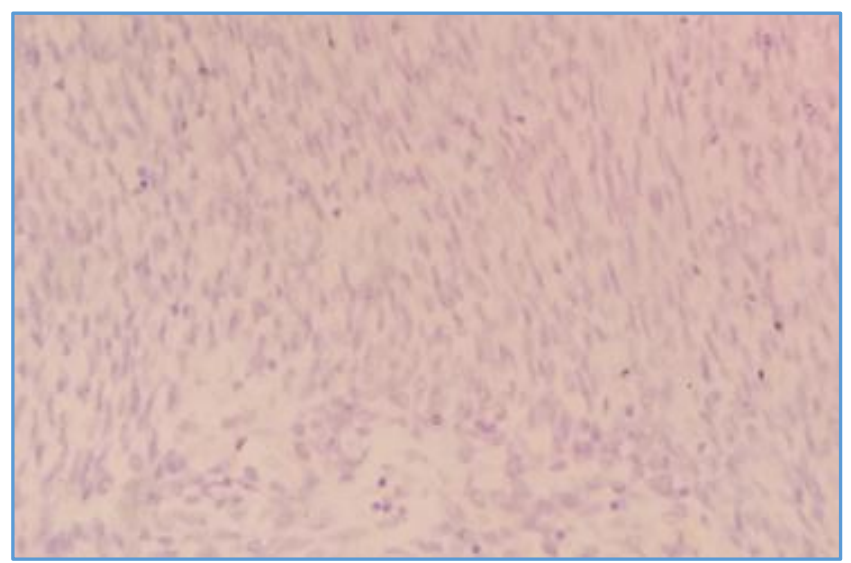

Figure 16. Tumour with Negative Staining for CD117

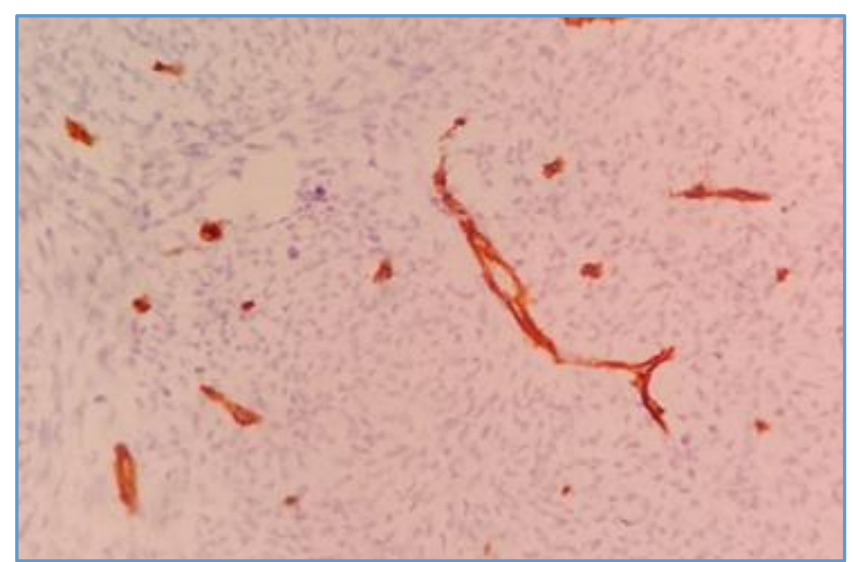

Figure 17. Tumour with Negative Staining CD34

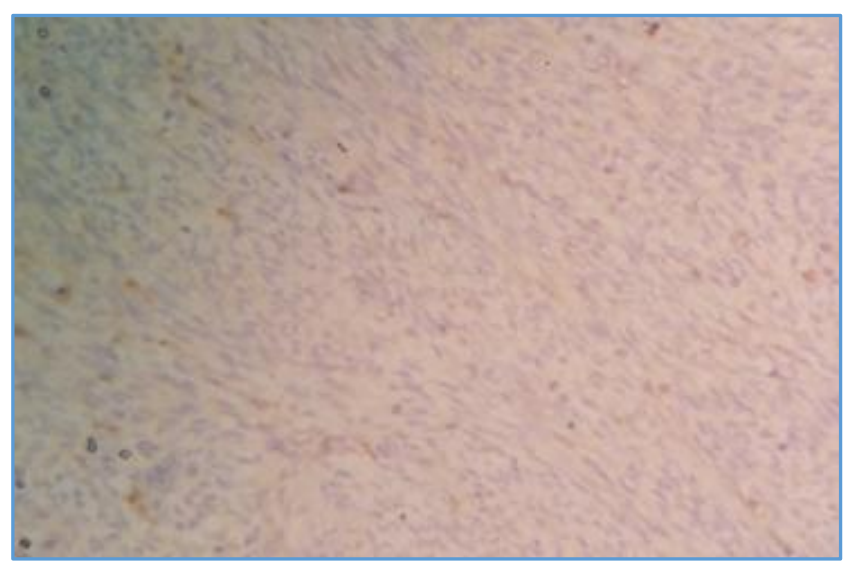

Figure 18. Tumour with Negative Staining CD99

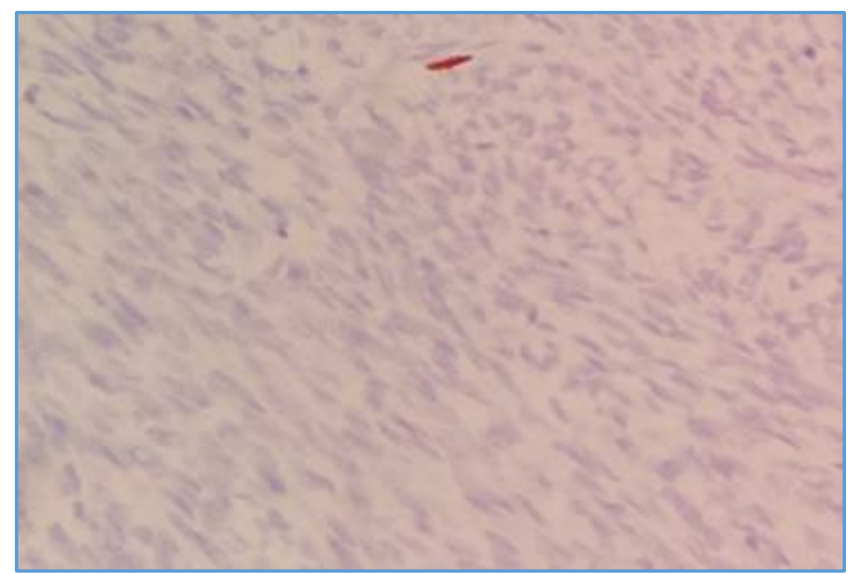

Figure 19. Tumour with Negative Staining Ki 67

\section{DISCUSSION OF MANAGEMENT}

Leiomyoma is a benign tumour that is potentially metastatic. Its growth depends on oestrogen and progesterone. ${ }^{2}$ Oestrogen has positive effect on tumour growth, whereas progesterone has a negative effect on tumour growth. Most of the patients have a history of uterine leiomyoma and/or myomectomy. In our case, patient had hysterectomy for leiomyoma 11 years back. It is usually an incidental finding on clinical or surgical evaluation. ${ }^{7}$ In the present case, patient presented with upper abdominal pain. On radiography, major findings include well-circumscribed solitary or multiple nodules ranging in size from a few millimetres to several centimetres. They resemble uterine leiomyoma in morphological and immunohistochemical level. They normally express ER and PR. In the present case, microscopic examination of haematoxylin and eosin slides has demonstrated features of smooth muscle cell differentiation. This was also confirmed by immunohistochemistry. Immunohistochemistry with Ki67 showed a low tumour cell proliferation index, which favours a benign behaviour of the tumour. Correlating with clinical, radiological, morphological and immunohistochemical features, we gave the final diagnosis as benign metastasising leiomyoma in pancreas and adrenal. There are many treatment options for BML. The first choice is surgery to remove the foci. ${ }^{2}$ The patients should be closely followed after surgery. The second option is hysterectomy, bilateral adnexectomy and long-term hormone therapy, which blocks the hormone release to stabilise the lesion. Our patient is on close follow-up.

\section{FINAL DIAGNOSIS}

Benign metastasising leiomyoma in pancreas and adrenal.

\section{REFERENCES}

[1] Houck WV, Broderick TJ, Cohen SA, et al. Benign metastasizing leiomyoma. Surgical Endoscopy 2002;16(4):716

[2] Chen S, Liu RM, Li T. Pulmonary benign metastasizing leiomyoma: a case report and literature review. Journal of Thoracic Disease 2014;6(6):E92-8.

[3] Steiner PE. Metastasizing fibroleiomyoma of the uterus: report of a case and review of the literature. Am J Pathol 1939;15(1):89-110.7.

[4] Yoon G, Kim TJ, Sung CO, et al. Benign metastasizing leiomyoma with multiple lymph node metastasis: a case report. Cancer Res Treat 2011;43(2):131-3. 
[5] Kang SA, Choi SI, Kim YA, et al. A case of benign metastasizing pulmonary leiomyoma. Tuberc Respir Dis 2005;58:614-8.

[6] Egberts JH, Schafmayer C, Bauerschlag DO, et al. Benign abdominal and pulmonary metastasizing leiomyoma of the uterus. Arch Gynecol Obstet 2006;274(5):319-22.
[7] Abramson S, Gilkeson RC, Goldstein JD, et al. Benign metastasizing leiomyoma: clinical, imaging and pathologic correlation. AJR Am J Roentgenol 2001;176(6):1409-13. 